\title{
CORRECTION
}

\section{Correction to: Societal and Ethical Impacts of Germline Genome Editing: How Can We Secure Human Rights? by Halpern J, O'Hara SE, Doxzen KW, Witkowsky LB, and Owen AL. CRISPR J 2019;2:293-298. DOI: 10.1089/crispr.2019.0042}

\author{
In the October 2019 issue of The CRISPR Journal (vol. 2, no. 5; 293-298) the article entitled "Societal and Ethical \\ Impacts of Germline Genome Editing: How Can We Secure Human Rights?" by Halpern et al. requires correction. \\ In the author byline on page 293, author Lea B. Witkowsky's name is misspelled. \\ The author byline originally states: \\ “Jodi Halpern, ${ }^{l, *}$ Sharon E. O'Hara, ${ }^{2}$ Kevin W. Doxzen, ${ }^{3, \dagger}$ Lea B. Witkowsy, ${ }^{3, \dagger}$ and Aleksa L. Owen ${ }^{2, "}$ \\ The author byline should now read: \\ Jodi Halpern, ${ }^{1, *}$ Sharon E. O’Hara, ${ }^{2}$ Kevin W. Doxzen, ${ }^{3, \dagger}$ Lea B. Witkowsky, ${ }^{3, \dagger}$ and Aleksa L. Owen ${ }^{2}$ \\ The online version of the article has been corrected to reflect this. The authors apologize for this error.
}

